\title{
DIGITAL PRACTICES TO ENHANCE INTANGIBLE CULTURAL HERITAGE
}

\author{
E. C. Giovannini ${ }^{1 *}$, M. Lo Turco ${ }^{1}$, A. Tomalini ${ }^{1}$
}

1 DAD, Dept. of Architecture and Design, Politecnico di Torino, Turin, Italy

(elisabettacaterina.giovannini, massimiliano.loturco, andrea.tomalini)@polito.it

KEY WORDS: 3D Models, Intangible Heritage, Digital Cultural Heritage.

\begin{abstract}
:
The term "cultural heritage" has been enriched with multiple contents in the last decades, partly thanks to the protection instruments developed by UNESCO. Despite the past, the cultural heritage is not limited to monuments and collections of objects. The term nowadays includes tangible and intangible cultural heritage (ICH). ICH includes traditions or living expressions inherited from our ancestors and passed on to our descendants, such as oral traditions, performing arts, social practices, rituals, festive events, knowledge and practices concerning nature and the universe or the knowledge and skills to produce traditional crafts. Within this context, the Museum of "Passione di Sordevolo" preserves and spreads the cultural and social value of the largest representation of popular Christian theatre in Italy, called "La Passione di Sordevolo". The paper presents the results of the research of the reconstructive modelling and visual storytelling project called "Digital historical scenic design". The project explores the use of digital technologies to create new content compatible with the Museum's mission: dissemination, communication and valorization of the documentary heritage (photographs, sketches, drawings) and the systematic collection of the oral tradition of this theatrical tradition.
\end{abstract}

\section{INTRODUCTION}

Interactive experiences are increasingly present in the Museum portfolio of products in addition to the traditional aim of the museum's approach in collecting, displaying and preserving objects and collections. Interactive storytelling and new technologies can enrich collections using novel narratives able to engage the public in different ways.

Digital technologies in museums have a great potential to assist both aspects of education and entertainment. Moreover, it is possible to customize and contextualize the information provided thanks to the role of the digital curation of contents. Through this approach it is possible to respond to different communication needs: while educational or specialist visitors require more detailed information about the collection and the museum; general visitors, on the other hand, desire a broad understanding and informal learning (Booth, 1998) by focusing more on the experience. The attention usually goes first on images then sounds and only at the end on texts.

"Digital historical scenic design. Reconstructive digital modelling of the sets used in the Passion of Sordevolo" presented in this paper, combines different levels of storytelling. The project began as a creative and technical partnership between the Museum of the Passione di Sordevolo and the Department of Architecture and Design of the Politecnico di Torino. The collaboration has the aim of promoting popular theatre performances using digital media, virtual environments and documentary heritage.

\section{STORYTELLING FOR MUSEUMS}

Psychologist Jerome Bruner explored the meaning and role of narrative for the creation and interpretation of human culture. In his volume "Acts of Meaning", he explores also the role of the narrative for museums.

Bruner initially identifies and explain the way people learning. He describes how humans, since their early stage of life, define themselves through storytelling and its shared form. Then he emphasizes how consequently the storytelling means taking a stance towards the subject matter. His study also states how the focus should be placed on the listener, emphasizing its role in the relationship with the narrator. During the storytelling, not all narrative sequences are resolved or described letting spaces that can be expanded by the listener's thoughts. This emotional connection between narration and the listener is the true power of storytelling. Within the museum environment, narratives connect visitors with objects. Images, sounds and informative content about the collections, make the visit more personal. The intention of creating emotions is nowadays often relying on digital elaborations that through animated images, sounds and reconstructions can help the process of connection between museum and visitor. The advent of digital technologies emphasizes how the Internet and social media, are the new challenge to museums whose first aim is to preserve and promote cultural heritage. Within this context, new forms of language and narratives are now available.

At the regard, museums can be divided into two groups:

- large museums that have invested in multichannel and multiplatform communication where museum curators themselves are becoming excellent communicators (Bonacini, 2020);

- small institutions with fewer resources, struggling to structure effective communication strategies.

The COVID-19 pandemic has only underlined how the digital transformation of the cultural sector is needed more than ever to recognize our heritage as an essential service to the citizen, as also stated, in Italy, by the Colosseum Decree No. 146/2015. Moreover, as Bonacini points out, the use of digital technologies can reduce the digital divide between the scientific world and the museum community towards sustainable democratization of culture.

However, the socio-cultural but also economic need to find new narratives to deliver cultural content risks intellectually leveling the research practices that underpin the creation of

\footnotetext{
* Although the contribution was conceived jointly, E. C. Giovannini is author of paragraphs 2.1, 3.1, 3.1.1; M. Lo Turco of paragraphs 1 and 4; A. Tomalini of paragraphs 2, 3, 3.1.2.
} 
this content.

Moreover, the ambiguity between the creation of content for dissemination purposes and the creation of content useful to enhance and authoritatively accredit the results obtained by research to the various interested users becomes clear.

\subsection{STORYTELLING FOR ICH}

Even more fragile than the tangible heritage, the intangible cultural heritage is an essential element in maintaining the memory of cultural diversity in the context of increasing globalization. The understanding of the intangible cultural heritage of different communities fosters intercultural dialogue and encourages mutual respect for other lifestyles.

The importance of intangible cultural heritage should not be limited to the cultural manifestation itself, but rather refer to the wealth of knowledge and skills that are transferred from generation to generation. The social and economic value is relevant to minority groups and traditional social groups within a country, and it is important to both developing and developed countries (Bortolotto, 2007).

Some of the characteristics of intangible cultural heritage, useful in defining in detail the scenario of this research project, is described below.

Intangible heritage is considered here:

- traditional, contemporary and alive at the same time, since it does not refer exclusively to traditions inherited from the past, but also to contemporary practices involving different cultural groups;

- inclusive, as it contributes to social cohesion by encouraging a sense of identity and responsibility that helps individuals feel part of one or more communities or society;

- representative, that is, simplified and dependent on those who work to transmit knowledge of traditions, skills and customs, from generation to generation, to their own or other communities;

- community-based: intangible cultural heritage is considered only when it is recognized by the communities, groups or individuals who create, maintain and transmit it.

\section{THE CASE STUDY: LA PASSIONE DI SORDEVOLO}

Sordevolo can be defined as a small island in the Prealps of Biella, where the values and traditions of a rural culture can still be felt. It is a place of faith and popular devotion, whose most emblematic expressions are the seven churches and the Passion play with its two hundred years of history.

In 1815 , the villagers made a vow to perform the play every 10 years if they were spared the plague that struck the village, and so the first performance took place in 1816 .

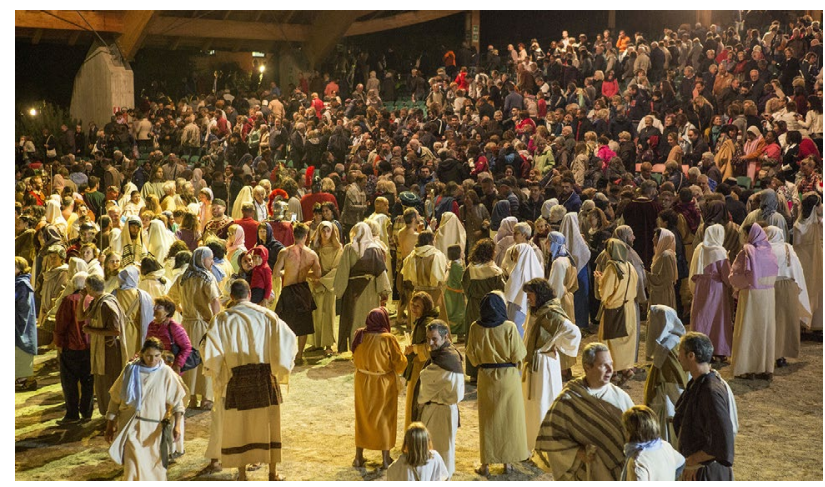

Figure 1. Actors and public on the stage of the Passione di Sordevolo. (C) Foto Perini Biella
The text of the play dates from the last years of the 15th century, a work written in verse by Florentine Giuliano Dati, chaplain of the Church of the Santi Martiri in Trastevere in Rome.

The play has evolved, from a religious performance to the present day as a popular secular theatrical show.

The Passione di Sordevolo is an event attended by almost $60 \%$ of the citizens. Today they meet every five years and invest a year to organise this performance.

The event is not reduced to a single play on one day but is performed for an entire summer. It is a tradition that goes beyond the theatrical moment and becomes a cultural, social and economic event that involves the whole community. For these characteristics, the Passione di Sordevolo must be considered unique in the panorama of Italian folklore.

The first representations of the Passion took place in various fields bordering the built-up area of Sordevolo, but today the representation is staged in an open space of about 4,000 square metres, where a reconstructed corner of Jerusalem from $33 \mathrm{AD}$ is set up.

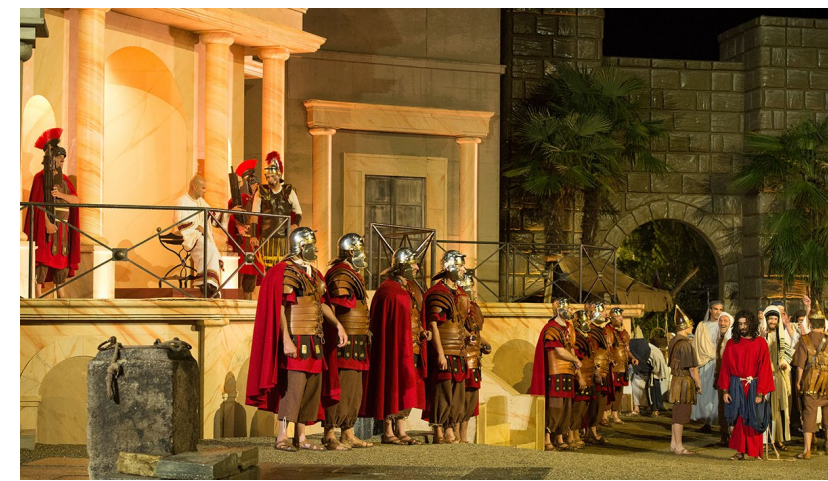

Figure 2. Scenography of a Cattedra with actors. (C) Foto Perini Biella

The performance lasts three hours and consists of a prologue and 29 scenes. The whole community is involved in the performance and about 400 residents take part in the show, while another 300 participate in various ways behind the scenes, making costumes, designing and building the set. The preparation for this event takes no less than two years. It is characteristic that many specific roles - played by ordinary citizens, not professional actors - are passed down from generation to generation (Associazione Teatro Popolare di Sordevolo, 2015; Gütermann, 2019).

In parallel to this event of international appeal, the Associazione Teatro Popolare di Sordevolo inaugurated in 2015 the Museo della Passione, set up in the choir and sacristy of the church of S. Marta. The proposed setting is not limited to the display of the scenic objects, but it is focused on the narration of the people who in various capacities have contributed to give life to this event during the various editions. The visitor can enjoy short films, photographs, documents and scenic objects, appreciating both the artistic sense and the soul - the Passion which is at the base of this sacred representation.

With the opportunity to renew the museum's interior design, the Associazione decided to integrate the physical collections with new digital contents.

This need has led to the collaboration with the Department of Architecture and Design of the Politecnico di Torino, through the research project entitled Digital historical scenic design: the purpose is to integrate the current exhibition itinerary with the use of new digital content designed for a non-specialized public. 


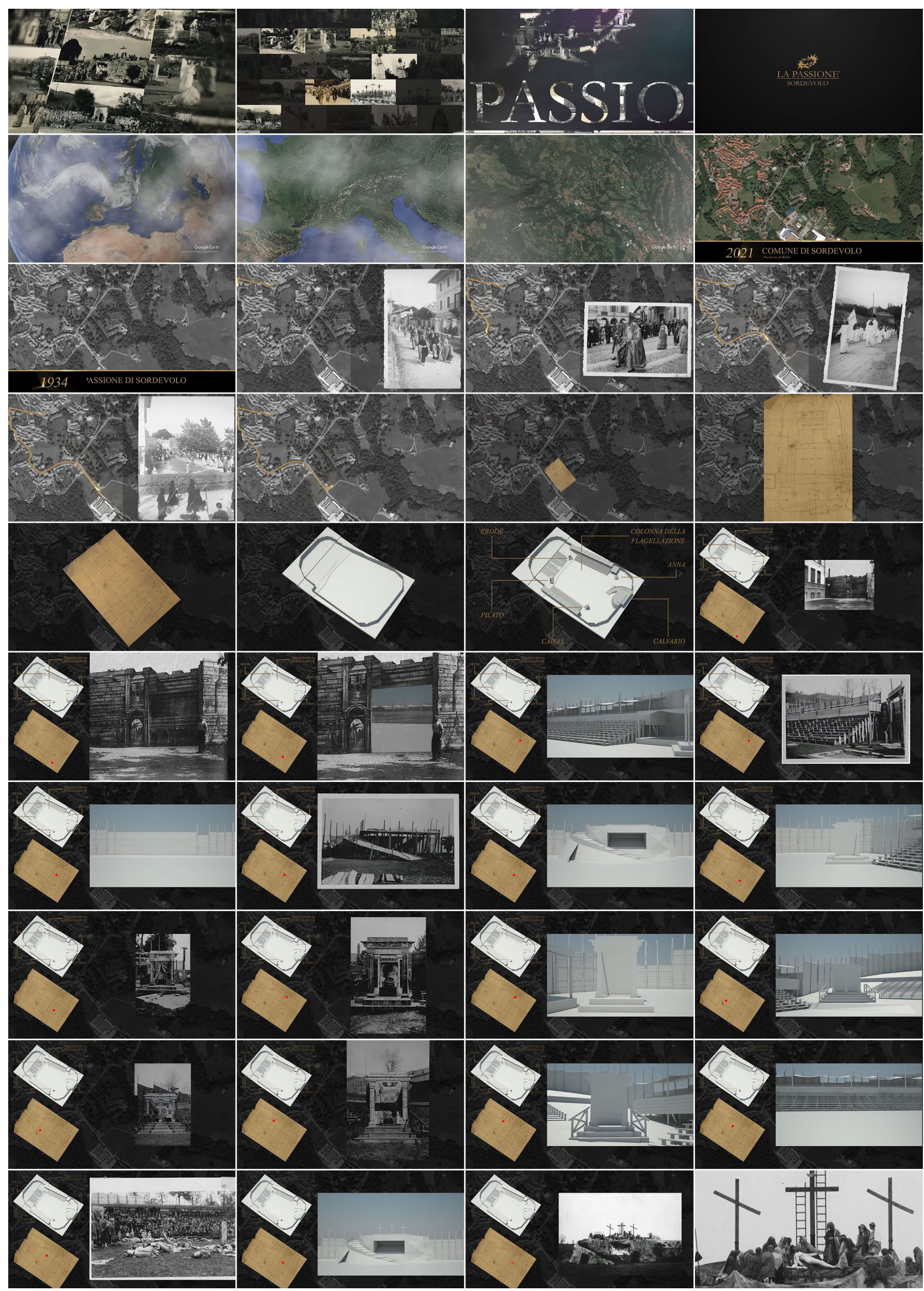

Figure 4. Storyboard of the video animation for Museo della Passione di Sordevolo. C E.C.Giovannini 


\subsection{A Visual-storytelling approach}

The purpose of the proposed storytelling is part of the panorama currently classified as video storytelling.

The creation of this type of content includes both ora storytelling (digital audio clips) and written storytelling (ad hoc texts that complete the video).

In addition to video storytelling, animated storytelling has also been defined to include 3D content consisting of the deconstruction of reality and its reconstruction in animated form. (Bonacini, 2020).

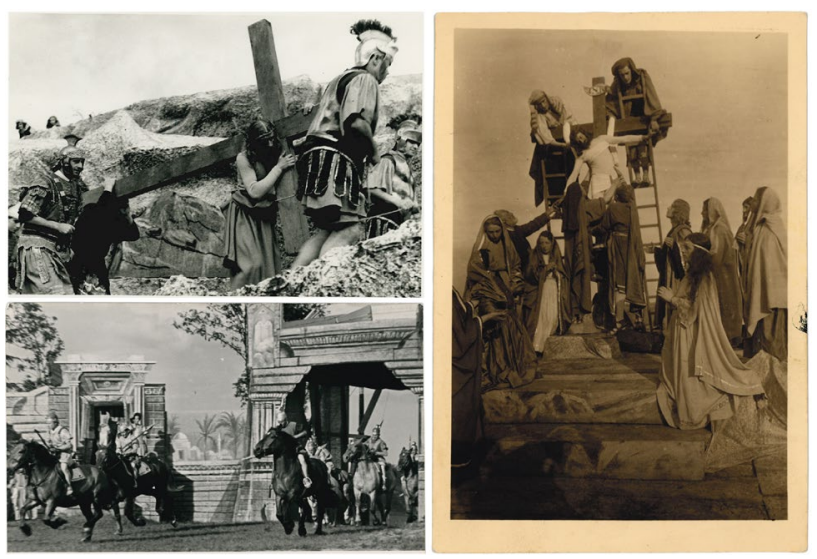

Figure 5. Collage with some historical pictures. (C) Archive of the Museo della Passione di Sordevolo

Digital historical scene design was therefore created to use 3D content to recreate the scenic aspects of the ancient theatrical performance of the Passione di Sordevolo by capturing two representative historical moments: 1934 and 1950, before and after the II World War.

In addition to three-dimensional modelling, using historical/archival and photographic documentation to reconstruct the digital environments, the focus was on the purpose of the narrative: to tell the story of how the theatrical performance plays out.

Historical images, carefully collected, catalogued and preserved in the archives of the Museum of Sordevolo, which have never been published, were chosen as the theme and thread of the narrative. The selection of the unpublished material was made in collaboration with the museum and its decision to renovate and redesign the museum itself. The redesign was largely based on photographic content to highlight material previously reserved for archivists and scholars.
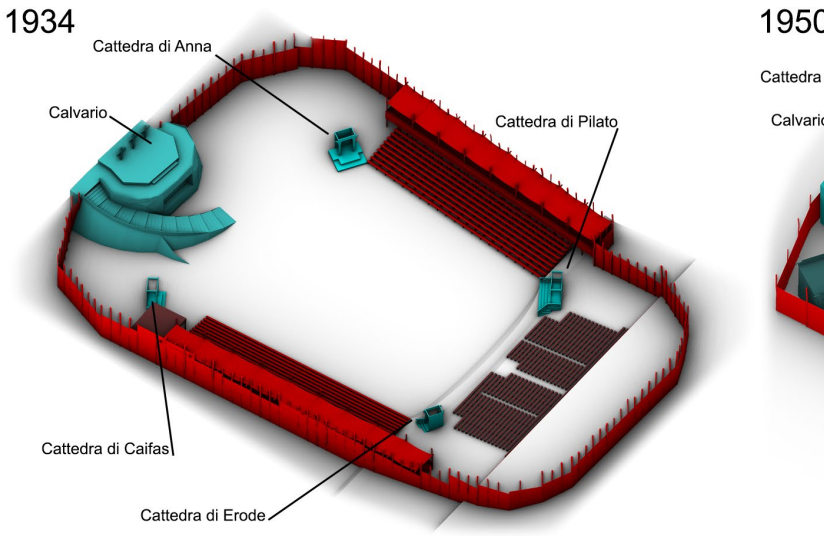

The video was then divided into three main moments:

- The Procession: in this first sequence, the visitors sees the route of the procession through the streets of Sordevolo, shown by an animated map with the help of a trail of light.

The image of the map is accompanied by historical photographs taken during the procession.

- the scenography in the amphitheatre: for the narrative inherent to the scenography, 3D was used to create the ancient scenography. The reconstruction of the environment was done by resorting different types of iconographic and documentary sources. A lot of space was also given here to the use of historical sources as a common thread between the sequences of images. In particular, the 3D scenes were designed to match the cameras in the virtual environment in 3D Studio Max.

This allowed for greater fluidity in the various scene changes that follow the real sequence of scenographic aspects of the theatrical representation. The use of cameras with the same point of view as the historical image allowed transitions with scenographic effects.

- the theatrical act: the final sequence focused instead on the use of photographs depicting the most important moments of the performance. In this case, the focus of the storytelling was on the musical theme and tone of the piece. Over the years, both the text and the sets and costumes have changed. Therefore, some actors were asked to perform the old texts from 1934 and 1950. In addition to the images, some of the passages recited by the actors were overlaid with the animated text, which picks up the vocal passage to accompany the visitor as they listen to it.

\subsubsection{The path on the map}

The Corteo della Passione di Sordevolo begins in the centre of the city and reaches the area of the amphitheatre, which has not been changed until today.

Between 34 and 50 the route changes, but the location of the buildings remains unchanged. For the creation of the map, we have therefore referred to the IGM map of 1968.

From Google Earth, the buildings that exist today were erased to simulate the historic city in 1934 .

An introductory scene was chosen for the narrative, in which a video extrapolated from Google Earth frames the village of Sordevolo. To emphasise the change in time, the use of infographics indicating the reference year and the use of black and white and ochre colours were chosen. The black and white refers to the past while making the photographic material, also in black and white, homogeneous. The ochre colour, on the other hand, recalls the official logo of the event.

After the framing scene, the animated route comes to life in conjunction with a sequence of historical images.

Figure 7. Synthetic model of the elements constructed for the Passion play (1935 and 1950) . C) A. Tomalini 


\subsubsection{The 3D models}

The basic material consists of the rich documentation archived by the Sordevolo Association: a rich photographic archive and the collection of an extensive documentary apparatus consisting of drawings, sketches, stage plans, documents of meetings, economic reports, some videos and a considerable press review of local newspapers.

A large amount of archival material formed the basis for the reconstruction phase. The preparatory phase consisted of collecting, selecting, analysing and digitising the sources; these were subdivided to identify the props most properly. The modelling phase also took into consideration the different quality and reliability of the information collected and how these affected the final result (Bianchini, Nicastro 2018).

- The first group of objects consists of the best-documented stage elements. Of some sets, there were not only photographs of the scene and some phases of the construction site, but also project drawings (some of which were cited) and relative construction details. In this case, accurate documentation allowed reconstruction at a higher level of quality.

- The second group of elements refers to other architectural components such as terraces or stands: there are no project drawings of these elements, only some sectional sketches to verify their dimensions and predict the number of spectators; although they are present in numerous images, they are not visible (due to seated people), there are other sketches, also in planimetric view, of their general dimensions and location, as well as some photographs of the construction site;

- The third group of objects includes smaller and less complex props that were not documented in detail, such as some furnishings that did not require detailed drawings for their construction and were borrowed from deaf-mute families.

For this reconstruction, we opted for a conceptual, even thematic representation, avoiding the pursuit of a hyper-realistic rendering that would not be congruent with the other materials on display. The models were created using software and the polygonal modelling method.

As noted above, not all elements of the set had technical drawings on which to rely, and photographic images, as perspective views, can only reproduce configurations known to the viewer, so it is essential to recognise the architecture present in the scene. We have therefore taken those architectural features that are found in several photographs and images to deconstruct the photographs and reconstruct the space of the set.
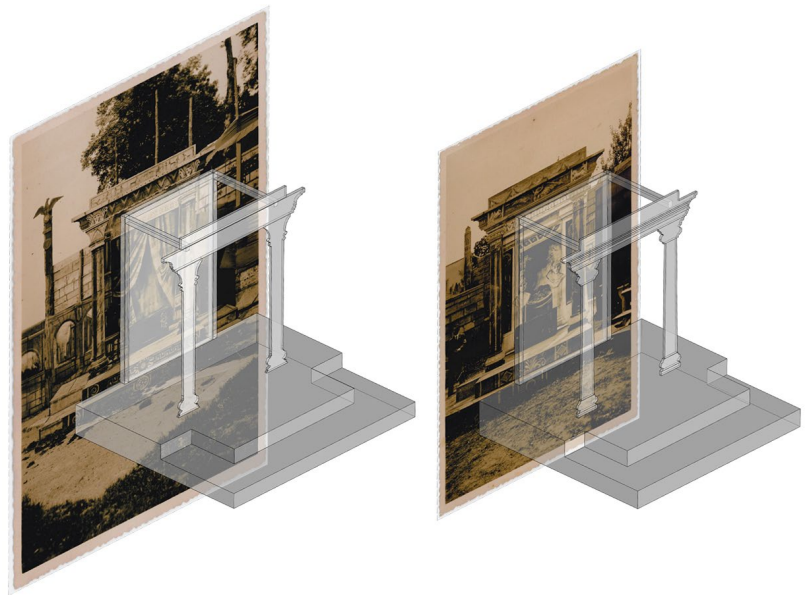

Figure 8. Re-source based virtual reconstruction (1934's historical photos) for Cattedra di Anna and Cattedra di Caifas. (C) A. Tomalini
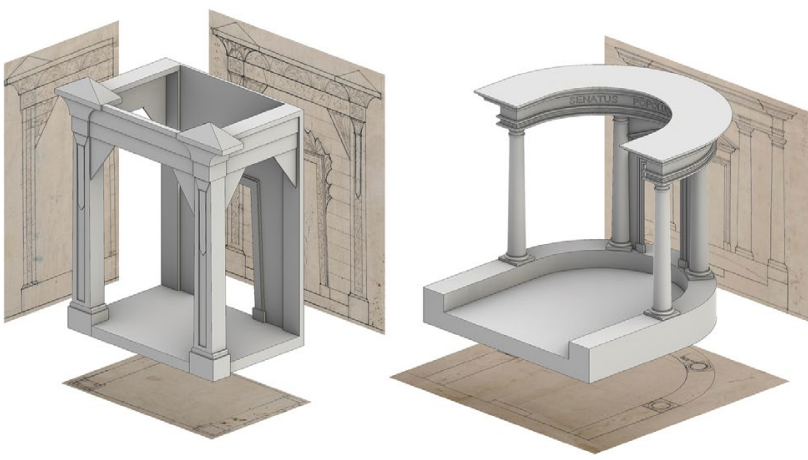

Figure 9. Re-source based virtual reconstruction (1950's archival documentation) for Cattedra di Erode and Cattedra di Pilato. (C) A. Tomalini

\subsubsection{The 3D animations}

Using the historical images selected by the Museo della Passione, the 3D software tools were used to identify the same viewing angles with cameras.

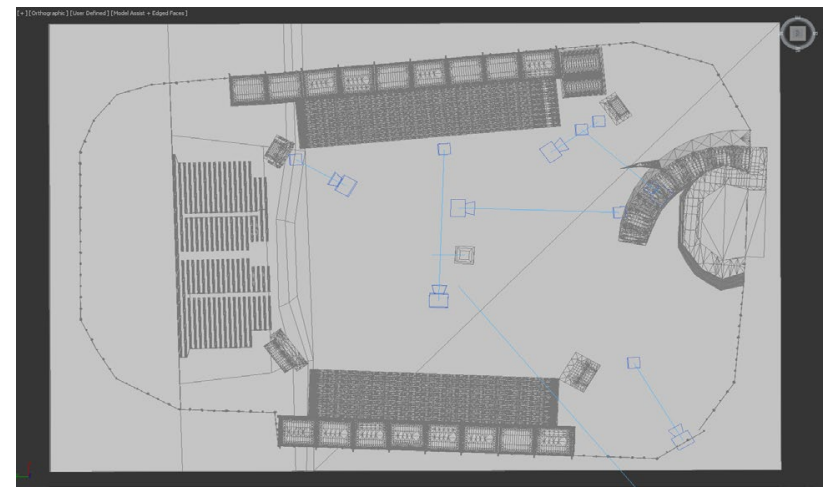

Figure 10. Top view of $3 \mathrm{ds}$ Max environment showing cameras used for animations. (C) E.C.Giovannini

Two types of animation have been developed:

- An animation that provides an overall view of the scenographic complex. This animation was also used as a page navigator throughout the virtual reconstruction sequence.

- Transition animation: animations that end or begin with cameras aligned with the viewpoint of the historical source.

For a correct perception of the space and the relationship between the elements of the scene and the audience, the reconstructions are first shown from a bird's eye view; then the camera moves to eye level within the edge of the stage and dwells on the main shots that characterise the two different theatrical performances.

We opted for a conceptual rendering to avoid striving for a hyper-realistic representation that is not congruent with the other showed materials.

The layout of the scenography in the amphitheatre consists of a scene divided into two main areas. On the left, it is possible to admire the original plan of the scenography.

This documentation for both 1934 and 1950 was used as a texture map inside the $3 \mathrm{ds}$ Max environment. The plane with the texture was used for a first transition between the sequence of the corteo and the sequence of scenography. From the old map, the $3 \mathrm{~d}$ model grows up following this sequence: the terrain, the fence, the wood stands with fabric covers and finally all the elements of scenography. 

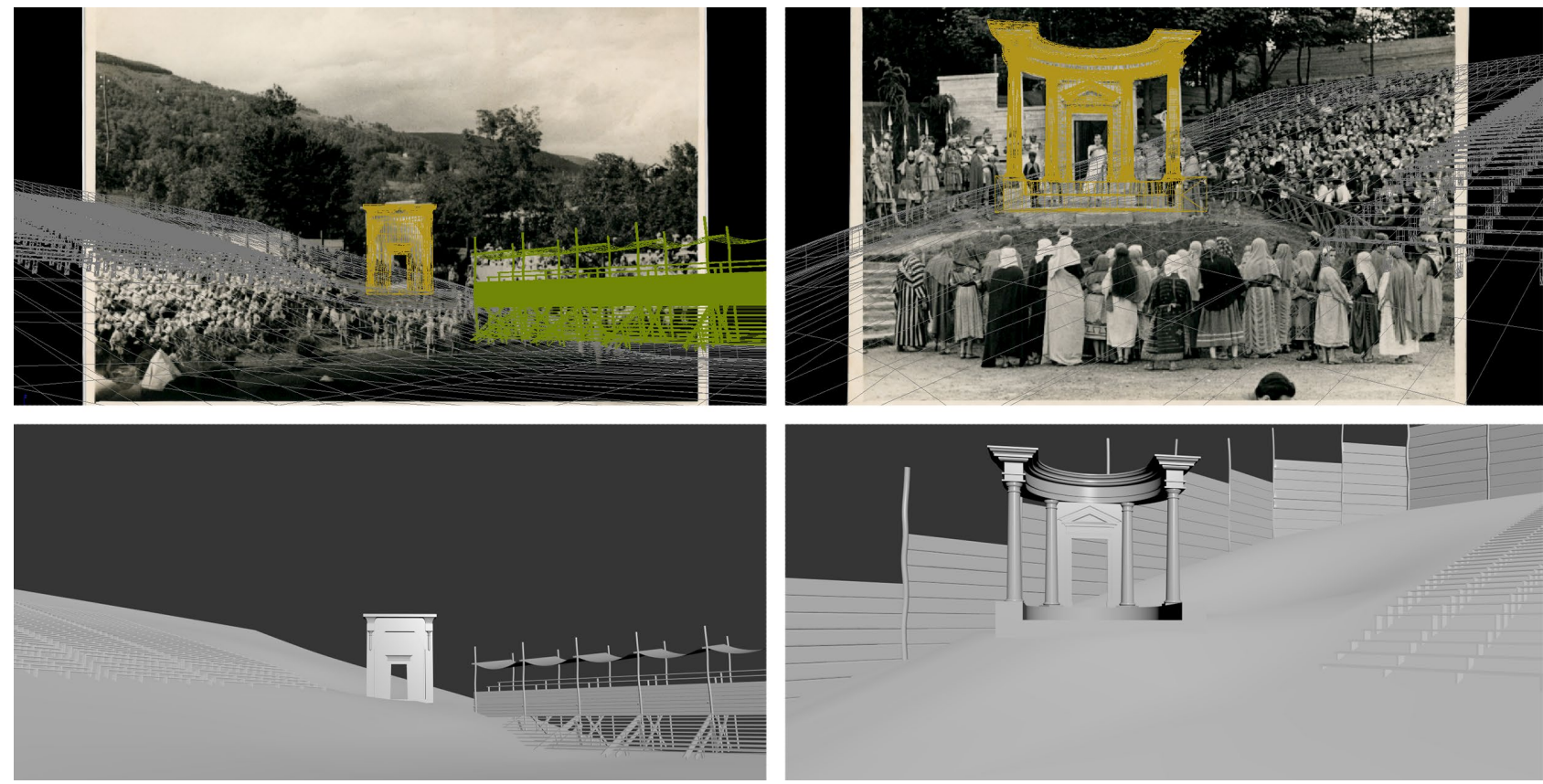

Figure 11. Camera matching between historical pictures and 3D models. C) E.C.Giovannini

The sequence of the 3D models are: Cattedra di Caifas, Cattedra di Anna, Cattedra di Pilato and Cattedra di Erode.

In the video animation, we chose to maintain the name of these elements because are characteristic of the theatrical representation. After the first animations, the 3D model completed is used as a map of elements, a legend that indicates the name of places. The historical plan is used as a navigator where a redpoint follows the camera movements indicating the point of view for each 3D scene.

The camera matching between historical pictures and the 3D models allows emphasizing the transition between the 3D sequences.

\section{RESULTS AND DISCUSSIONS}

The case study is the result of a multidisciplinary work in which historians and architects and actors have worked together to model the scenography of a theatrical representation of the Passione di Sordevolo. An interesting case of intangible heritage that the community of Sordevolo preserves first of all in its memory and then in its Museum.

Digital visualization in visual storytelling, as a representation of a past that no longer exists, is nowadays a communicative necessity and is a possible answer to the need to preserve, communicate and promote the cultural value of theatre arts.

The virtual reconstructions become a means of experiencing a time otherwise intangible but recognizable in historical images, videos and documentary heritage.

The storytelling here presented is an expression of a methodology that aimed to provide a possible response to the creation of cultural content capable of engaging a new audience in the Museum sector and make alive historical pictures using diverse methods: with animated maps, with 3D environments and with audio tracks.

From a disciplinary point of view, the use of $3 \mathrm{D}$ models in storytelling is also a possible way to disseminate the outcomes of research in the field of virtual reconstructions but in this case, the role of $3 \mathrm{D}$ was to recreate an emotional engagement with the public.

The produced video animation will be part of the permanent exhibition of the Museum of the Passion in Sordevolo and was designed considering as primary public, the citizens of Sordevolo and the spectators of the play.

\section{ACKNOWLEDGMENTS}

The research project "Digital historical scenic design" was made in collaboration with the Associazione Teatro Popolare di Sordevolo and partially funded by Fondazione CRT.

\section{REFERENCES}

Associazione Teatro Popolare di Sordevolo, 2015. La Passione di Sordevolo. Immagini e parole. Gaglianico (BI): Botalla Editore.

Bianchini C., Nicastro S. (2018). La definizione del Level of Reliability: un contributo alla trasparenza dei processi di Historic-BIM. Dn - Building Information Modeling, Data \& Semantics, 2, pp. 45-59.

Bonacini E. (2020). I musei e le forme dello storytelling digitale. Roma: Aracne.

Booth B. (1998). Understanding the information needs of visitors to museums. Museum Management and Curatorship, 2:139-157.

Bruner J. (1990). Acts of Meaning. Cambridge, MA: Harvard University Press.

Greco C. (2019). La biografia degli oggetti. Rivoluzione digitale e Umanesimo. In: Ciccopiedi C. (ed.), Archeologia invisibile. Catalogo della mostra. Modena: Franco Cosimo Panini Editore.

Gütermann C. F. (2019). Sordevolo. Dove la Passione opera. Gaglianico (BI): Botalla Editore. 